\title{
Correlates of Health Literacy among Filipinos aged $50-70$ years old Belonging to Low-Income Families in a Selected Community
}

\author{
Hygeia Grace C. Agosto, ${ }^{1}$ Marla Vina A. Briones, ${ }^{2}$ and Maylin C. Palatino ${ }^{1}$ \\ ${ }^{1}$ Department of Epidemiology and Biostatistics, College of Public Health, University of the Philippines Manila \\ ${ }^{2}$ College of Public Health, University of the Philippines Manila
}

\begin{abstract}
Objective. A number of studies worldwide have shown that health literacy is vital in the improvement of health status of individuals as well as in the effective implementation of health programs. In the Philippines, however, data regarding the level of health literacy among Filipino adults are yet to be gathered. This study then aimed to describe the health literacy level and to determine the correlates of health literacy among Filipino adults aged 50 to 70 years old belonging to the lower socioeconomic class in a selected community.
\end{abstract}

Methods. An analytical cross-sectional study was conducted, utilizing data from the study of Briones, M. et. al in 2015, among selected Filipino adults in a barangay in Pasig City.

Results. Ninety-four percent of the study participants had problematic/inadequate health literacy level. The factors found to be statistically associated with having problematic / inadequate health literacy were having at most high school level education, and not being able to visit a medical doctor in the past 12 months. Nonetheless, being self-employed made an individual less likely to have a problematic/inadequate health literacy.

Conclusions. There was a high proportion of individuals who had problematic/inadequate health literacy among 50 to 70 years old in the study area. Socio-economic characteristics such as educational attainment and healthcare access were shown to be associated with an individual's level of health literacy. Despite the extensive health information available to the public, the level of health literacy still remained to be poor. This indicates that there is a need to evaluate if said information are easily accessed, understood, appraised and applied by individuals to make sound health decisions.

Key Words: health literacy, health education, health behavior, correlates, low income, poverty

\section{INTRODUCTION}

Corresponding Author: Hygeia Grace C. Agosto, BSPH, MPH Department of Epidemiology and Biostatistics College of Public Health University of the Philippines Manila 625 Pedro Gil Street, Ermita Manila 1000 Philippines Telephone: +6325247118

Email: hcagosto@up.edu.ph
Many diseases, whether communicable or noncommunicable, can be prevented or treated at an early stage if individuals have the ability to make appropriate health decisions. This is the concept of health literacy, which encompasses the process of accessing, understanding, appraising and applying health information. ${ }^{1}$

Globally, a number of countries have studied the level of health literacy in their particular settings. ${ }^{2-6}$ Some also found that health literacy is associated with the improvement of the health status of individuals. In addition, having knowledge of a population's health literacy helps evaluate the progress of health programs being implemented.

Moreover, several studies have found that occupation or employment, ${ }^{1}$ older age, ${ }^{7}$ low educational attainment, ${ }^{8,9}$ 
race, ${ }^{9}$ low socioeconomic status, ${ }^{10}$ marital status, ${ }^{10}$ and poor literacy ${ }^{11}$ are associated with having poor health literacy.

In the Philippines, however, health literacy is yet to be explored and strengthened. Even though the country has a relatively high basic literacy rate of $95.6 \%$ based on the Functional Literacy, Education and Mass Media Survey done by the National Statistics Office in 2008, this does not necessarily translate to having high health literacy rate. According to Dr. Anthony Leachon of the Philippine College of Physicians, patients come to health care professionals to seek medical advice when they are already very sick. He further explained that this is a failure of health literacy. ${ }^{12}$ Many Filipinos are unhealthy and get severe illness, which may have been brought about by low health literacy. ${ }^{12}$ Although a National Health Literacy Act was filed by former Sen. Miriam Defensor-Santiago last 2008; at present, it is still pending for approval. ${ }^{13}$

In addition, the country's older population is increasing as noted by the 2000 Census of Population and Housing that $5.97 \%$ of Filipinos are senior citizens. This number was expected to reach seven million in 2010 and to double in approximately 16 years. The potential impact of healthcare costs in a rapidly aging population, due to severe disability from morbidity or other health conditions, will become evident in the country's economy as well. ${ }^{14}$ Old and older Filipino adults must be equipped with the needed knowledge and skills regarding what is best for their health so that they can move and care for themselves dependently, lessening the burden of healthcare costs to their families and communities.

As such, it is important to find information about the level of health literacy of Filipino adults to help the healthcare system create appropriate interventions that will enhance health literacy. This is considered to greatly contribute in reducing disease morbidity and mortality in a population.

This study was conducted only among older adults belonging to low-income families in a barangay in Pasig City. However, these individuals were deemed appropriate for the study since their levels of health literacy must be identified to craft programs and policies that would be useful in improving their health status. Hence, inferences from this study pertain only to the older adults belonging to said community.

This study aimed to (1) describe the health literacy level and (2) determine the correlates of health literacy among Filipino adults aged 50 to 70 years old in a selected community.

\section{METHODS}

\section{Study design, population and setting}

An analytical cross-sectional design was applied using the data of the 2015 study of Briones, M. et al entitled "Health Literacy among Filipino Adults Belonging to LowIncome Families and its Association with Cancer Screening Utilization: A Cross-Sectional Study". ${ }^{15}$ Its general objective was to determine the relationship between health literacy and cancer screening utilization among Filipino adults aged 50-70 years old belonging to low-income families in a selected community.

Participants of the said study included Filipino adults from low-income families, aged 50-70 years old, residing in a barangay in Pasig City. This barangay was chosen since majority of the population belongs to poor and low-income families and it is also the biggest informal settlement area in Pasig City. Low-income families, as defined by Virola, et $\mathrm{al},{ }^{16}$ was based on two factors of annual family income and family size.

Briones, M. et al utilized cluster random sampling design to select the study participants, getting a total of 2,036 eligible participants. This paper included all these participants.

\section{Methods of data collection and data collection instrument}

Data of the study of Briones, M. et al were collected through a face-to-face interview by trained interviewers using an interview schedule that underwent expert validation and pilot testing.

The 15 to 30-minute interview was administered in Filipino. The instrument was translated to Filipino from the original English version by the Sentro ng Wikang Filipino of the University of the Philippines Manila.

The first part of the interview asked information about the socio-demographic profile, healthcare access, insurance coverage and risk of cancer of participants.

On the other hand, the second part of the interview, which was adapted from the Health Literacy Survey AsiaQuestionnaire (HLS-EU-A-Q), was used to determine the health literacy index. The original tool was composed of 5 parts but only the Health Literacy Survey portion was used in this study to measure an individual's health literacy index. There were 47 questions used to assess the ability of the participants to find, understand, judge and apply health information on health care, disease prevention and health promotion. The participants then chose from 4 categories of responses ranging from "very easy" to "very difficult" in each statement.

\section{Data Processing and Analysis}

In the Briones, M. et al study, field editing was done by the interviewers after the conduct of the interviews, while completeness and consistency of the forms were checked by the field supervisor upon submission by the interviewers. Coding, encoding and machine editing were conducted using Epi Info7 software and Stata/SE Version 12. Once the data set of Briones, M. et al was obtained, the authors of this paper did further data processing to include checking for completeness and recoding of variables.

The health literacy survey was set to a metric of 0 to 50 in order to allow the computation of the general health literacy index using the formula applied in the study of Fullam. ${ }^{7}$ 
Originally, based on the computed health literacy index of Briones, M. et al, respondents were classified into 4 categories, namely the following: (1) Excellent - score of >42-50, (2) Sufficient - score of >33-42, (3) Problematic - score of > 2533 , and (4) Inadequate - score of 0-25. However, for this study, we merged the categories of Excellent and Sufficient, while Problematic and Inadequate levels were lumped together. As such, there were two final categories, which are (1) Excellent/sufficient and (2) Problematic/inadequate levels of health literacy.

Means and standard deviations (SD) were computed for monthly family income while frequencies and percentages were obtained for the rest of the variables, which were all qualitative in nature.

The researchers utilized multiple logistic regression to determine which of the collected independent variables were associated with health literacy level. Backward elimination was employed in variable selection. Odds ratios (OR), their corresponding $90 \%$ confidence intervals and $\mathrm{p}$-values were obtained. A 10\% level of significance was used. All analyses were done using Intercooled Stata Version 12.

\section{Ethical Considerations}

An ethical clearance to conduct the main study was granted by the University of the Philippines Manila Research Ethics Board.

Informed consent was obtained prior to the interview. In case the participant was unable to read and write, a witness, who was someone known to him/her, was required to be present. Each participant was assigned a unique identification number and his/her name was not included when data were being encoded for analysis. Answered questionnaires were also kept in a locked filing cabinet.

The only potential risk associated in study participation was the discomfort that might be experienced by the participant while addressing queries on personal information. However, this concern was addressed by informing study participants beforehand that they do not have to answer questions they regard to be very personal and information will be treated with utmost confidentiality.

\section{RESULTS}

Out of the 2,036 participants, $93.8 \%$ (90\% CI: $92.6 \%$, 94.8\%) had problematic or inadequate health literacy level.

The characteristics of the study participants are shown in Table 1. Most of the participants had at least one relative with medical training (92.4\%), 47\% claimed to have visited a doctor for the past 12 months, and more than half had a health insurance (54.4\%).

Table 2 presents the crude association of each of the factors with having problematic or inadequate health literacy. Without controlling for the effect of any other variable, having low educational attainment, being self-employed, not having health insurance or not visiting a doctor in the
Table 1. Characteristics of the participating Filipino residents of a certain barangay, Pasig City, $2015(n=2,036)$

\begin{tabular}{|c|c|}
\hline Characteristic & No. (\%) \\
\hline \multicolumn{2}{|l|}{ Sex } \\
\hline Male & 810 (39.9) \\
\hline Female & $1,226(60.2)$ \\
\hline \multicolumn{2}{|l|}{ Age } \\
\hline $50-59$ & $1,164(57.2)$ \\
\hline $60-70$ & $872(41.8)$ \\
\hline Monthly family income (mean \pm SD) & $11,711.8 \pm 9,011.8$ \\
\hline \multicolumn{2}{|l|}{ Marital status } \\
\hline Single & $98(4.8)$ \\
\hline Live-in/Married & $1,474(71.4)$ \\
\hline Separated / divorced & $83(4.1)$ \\
\hline Widowed & $381(18.7)$ \\
\hline \multicolumn{2}{|l|}{ Educational attainment } \\
\hline At most Elementary graduate & $843(41.4)$ \\
\hline High School level / High School graduate & $930(45.7)$ \\
\hline At least college level & $263(12.9)$ \\
\hline \multicolumn{2}{|l|}{ Employment status } \\
\hline Employed & $1,114(54.7)$ \\
\hline Self-employed & $567(27.9)$ \\
\hline Unemployed & $355(17.4)$ \\
\hline \multicolumn{2}{|l|}{ Health insurance } \\
\hline With & $1,107(54.4)$ \\
\hline Without & $929(45.6)$ \\
\hline \multicolumn{2}{|l|}{ Visited doctor for the past 12 months } \\
\hline Yes & $961(47.2)$ \\
\hline No & $1,073(52.8)$ \\
\hline \multicolumn{2}{|c|}{ Having at least one relative with medical training } \\
\hline Yes & $156(7.7)$ \\
\hline No & $1,880(92.4)$ \\
\hline
\end{tabular}

past 12 months increased the odds of having problematic or inadequate health literacy.

As shown in Table 3, adjusting for the other significant factors, those with high school level education were twice as likely to have inadequate health literacy than those who have higher education level. Moreover, the odds of having low health literacy level was 4.4 higher among those who had finished at most the elementary level than those who had college education. Being self-employed was found to be protective against low health literacy level than being employed. Finally, not visiting a doctor in the past year increased the odds of having problematic or inadequate health literacy level by $40 \%$.

\section{DISCUSSION}

Based on the findings of this study, majority of the study population of Filipino adults aged 50-70 years old in an urban poor community have problematic or inadequate level of health literacy (93.8\%). Compared to other Asian countries $^{17-19}$ wherein problematic or inadequate level of health literacy in the general population ranged from $54-85 \%$, the obtained estimate was considerably higher. The difference may be due to the disparity in the study populations - general population and old adults in the other Asian countries and 
Table 2. Result of simple logistic regression for unadjusted association of the individual factors with having problematic/inadequate health literacy, Pasig City, 2015

\begin{tabular}{|c|c|c|c|}
\hline Factor & $\begin{array}{l}\text { No. with inadequate or problematic } \\
\text { health literacy / total (\%) }\end{array}$ & $\begin{array}{c}\text { Crude Odds ratio } \\
\text { (90\% Confidence Interval) }\end{array}$ & p-value \\
\hline \multicolumn{4}{|c|}{ (1) } \\
\hline Male & 576 / 810 (93.3) & 1.0 & \multirow{2}{*}{0.516} \\
\hline Female & $1,153 / 1,226(94.1)$ & $1.1(0.8,1.5)$ & \\
\hline \multicolumn{4}{|l|}{ Age } \\
\hline $50-59$ & $1,084 / 1,164$ (93.1) & 1.0 & \multirow{2}{*}{0.172} \\
\hline $60-70$ & 872 / 825 (94.6) & $1.3(0.9,1.8)$ & \\
\hline Monthly family income** & - & $1.0(1.00,1.00)$ & 0.341 \\
\hline \multicolumn{4}{|l|}{ Marital Status } \\
\hline Single & 89 / 98 (90.8) & 1.0 & \multirow{4}{*}{$\begin{array}{l}0.308 \\
0.147 \\
0.120\end{array}$} \\
\hline Live-in/Married & 1,378 / 1,474 (93.5) & $1.5(0.8,2.7)$ & \\
\hline Separated / divorced & 80 / 83 (96.4) & $2.7(0.9,8.3)$ & \\
\hline Widowed & 362 / 381 (95.0) & $1.9(1.00,3.9)$ & \\
\hline \multicolumn{4}{|l|}{ Educational Attainment } \\
\hline At most Elementary graduate & 815 / 843 (96.7) & $2.2(1.5,3.1)$ & \multirow{3}{*}{$\begin{array}{l}<0.001^{*} \\
<0.001^{*}\end{array}$} \\
\hline High School (HS) level / HS graduate & 867 / 930 (93.2) & $4.6(3.0,7.1)$ & \\
\hline At least college level & 227 / $263(86.3)$ & 1.0 & \\
\hline \multicolumn{4}{|l|}{ Employment status } \\
\hline Employed & $1,063 / 1,114(95.4)$ & 1.0 & \multirow{3}{*}{$\begin{array}{c}<0.000^{*} \\
0.106\end{array}$} \\
\hline Self-employed & $515 / 567(90.8)$ & $0.5(0.4,0.7)$ & \\
\hline Unemployed & 331 / 355 (93.2) & $0.7(0.4,1.0)$ & \\
\hline \multicolumn{4}{|l|}{ Having health insurance } \\
\hline With & $1,028 / 1,107(92.9)$ & 1.0 & \multirow[b]{2}{*}{$0.068^{*}$} \\
\hline Without & $881 / 929$ (94.8) & $1.4(1.0,1.9)$ & \\
\hline \multicolumn{4}{|l|}{ Visited doctor for the past 12 months } \\
\hline Yes & 889 / 961 (92.5) & 1.0 & \multirow{2}{*}{$0.029^{*}$} \\
\hline No & 1,018 / 1,073 (94.9) & $1.5(1.1,2.0)$ & \\
\hline \multicolumn{4}{|c|}{ Having at least one relative with medical training } \\
\hline Yes & 144 / 156 (92.3) & 1.0 & \multirow{2}{*}{0.435} \\
\hline No & $1,765 / 1,880(93.9)$ & $1.3(0.8,2.2)$ & \\
\hline
\end{tabular}

* significant at 0.10 significance level

${ }^{* *}$ treated as quantitative variable

Table 3. Significant correlates of health literacy among Filipino adults aged 50 to 70 years old, Pasig City, 2015

\begin{tabular}{lcc}
\multicolumn{1}{c}{ Correlate } & $\begin{array}{c}\text { Adjusted Odds Ratio } \\
\text { (90\% Confidence Interval) }\end{array}$ & p-value \\
\hline Educational Attainment* & $2.1(1.5,3.1)$ & 0.001 \\
High School (HS) level / HS graduate & $4.4(2.9,6.8)$ & $<0.000$ \\
At most Elementary graduate & $0.5(0.3,0.7)$ & $<0.000$ \\
\hline Self-employed vs employed & $1.4(1.0,1.9)$ & 0.066 \\
\hline Did not visit a doctor in the past 12 months & \\
\hline
\end{tabular}

${ }^{*}$ reference group was at least college level

this study, respectively, as well as the contrast in the socioeconomic composition of the participants.

However, it should be noted that measurement of health literacy may be misleading such that information bias may have occurred. This may be because the data collection tool was too lengthy that some respondents may have felt that certain questions were redundant. Thus, hasty responses would have been provided, which may lead to misclassification of respondents on their health literacy level.

Having a high school level education $(\mathrm{p}=0.001)$ and at most an elementary level education $(\mathrm{p}<0.001)$ were significantly associated with having a problematic or inadequate level of health literacy. These findings are similar to those shown by other studies ${ }^{8,9}$ that an individual's education actually affects his/her capacity to be health literate. One of the four components of health literacy is for an individual to be able to understand health information; as such, individuals with low levels of education might have difficulties in comprehending concepts related to health. Moreover, they would also find it hard to judge if the health information they have accessed is indeed reliable. It should also be noted that for individuals to be able to apply health information, they need to have the opportunities to do so, i.e. being able to live in a community with facilities promoting healthy lifestyle. An individual with a low socio-economic status might not have this said opportunity, stemming from the reason that he/she has a low level of education or was not able to finish a college degree. 
Not visiting a doctor in the past year was also associated with having a problematic or inadequate level of health literacy ( $p<0.001)$. This result is the same as that presented by a previous study ${ }^{20}$ in which lack of healthcare access results to lower health literacy levels. Moreover, it is possible that having frequent doctor visits increases health literacy among individuals since they rely primarily on their healthcare providers in obtaining health information. ${ }^{21}$

Regarding employment status, it is essential to note that being self-employed was found to be a factor $(\mathrm{p}=0.066)$ that less likely makes an individual have a problematic or inadequate level of health literacy. Although Sorensen, et. al mentioned that employment is associated with a person's level of health literacy, ${ }^{1}$ it is still unclear why being selfemployed, compared to being employed in a regular job, was a protective factor against a problematic or inadequate level of health literacy. Upon additional inspection of the data, it was found that there was a higher percentage of employed individuals in the older age group, i.e. 60-70 years old while for self-employed individuals, a higher proportion came from the 50-59-year-old group. Moreover, if age was treated quantitatively in this study, it was found to be crudely associated with level of health literacy $(\mathrm{p}=0.081)$ wherein older age increased the odds of having problematic or inadequate level of health literacy by $3 \%$. As such, this could be the probable reason why self-employment protected an individual from having a poor level of health literacy because most of them belonged to the 50-59-year-old group. However, these findings are unique to the data gathered for this study. Further studies must then be done to explain characteristics of self-employed individuals that make them more health literate.

\section{CONCLUSIONS AND RECOMMENDATIONS}

It is quite alarming to state that approximately $94 \%$ of the study participants had problematic or inadequate level of health literacy. Furthermore, as seen in previous studies, characteristics such as educational attainment and healthcare access, i.e. visit to a medical doctor in the past 12 months were shown to be associated with an older individual's health literacy level.

It must be stressed that despite the extensive health information available to the public, the level of health literacy of older individuals remains to be poor. There is then a need to evaluate if said information are easily accessed and understood by Filipino adults who belong in the lower socioeconomic class with a high school or elementary level of education. Healthcare access should also be improved by making sure that individuals are able to get medical advice as soon as it is necessary. The various roles of healthcare providers and that of PhilHealth must then be emphasized, wherein healthcare professionals give more time and effort in explaining health information and assure that these are understood by individuals; on the other hand, PhilHealth, as the national health insurance program, must intensify disseminating information about health services that may be availed by their members and guarantee that said information reaches individuals belonging to the low socioeconomic groups as well.

For future studies, it would be better if assessment of the level of health literacy would be done in the general population since this study was limited only to the older population in a poor community. In addition, a shorter version of the Health Literacy Survey should be used, if feasible, to have a finer measurement of an individual's level of health literacy.

\section{Acknowledgments}

The authors would like to express their gratitude to the Asian Health Literacy Association for permitting the use of the Health Literacy Survey-Asia Questionnaire.

\section{Statement of Authorship}

All authors have approved the final version submitted.

\section{Author Disclosure}

All authors have declared no conflict of interest.

\section{Funding Source}

No external funding.

\section{REFERENCES}

1. Sørensen, K., Van den Broucke, S., Fullam, J. et al. Health literacy and public health: A systematic review and integration of definitions and models. BMC Public Health. 2012; 12:80.

2. Oldach B, \& Katz, M. (2013). Health Literacy and cancer screening: A systematic review. [Online] Patient Educ Couns. Retrieved December 5, 2013, from http://dx.doi.org/10.1016/j.pec.2013.10.001

3. Baker D, Feinglass J, Thompson J, Gazmararian J, \& Huang, J. (2007). Health literacy and mortality among elderly persons. Archives of Internal Medicine, 167(14): 1503-9.

4. Schillinger D, Grumbach K, Piette J, Bindman, A. et al. Association of health literacy with diabetes outcomes. JAMA. 2002 Jul 2431;288(4):475-82.

5. Baker D, Gazmararian J, Williams M. et al. (2002) Functional health literacy and the risk of hospital admission among Medicare managed care enrollees. American Journal of Public Health, 92(8):1278-83.

6. Murray M, Wu J, Tu W. et al. (2004). Health literacy predicts medication adherence. Clinical Pharmacology \& Therapeutics, 75:76.

7. Fullam, J. (2012). The European health literacy survey: results from Ireland.

8. Manganello, J. Health literacy and adolescents: a future and agenda for future research. Health Educ Res. 2008;23(5):840-847.

9. Miller D, Brownlee C, McCoy T, \& Pignone M. The effect of health literacy on knowledge and receipt of colorectal cancer screening: a survey study. BMC Family Practice. 2007;8:16.

10. Javadzade S, Sharifirad G, Radjati F, Mostafavi F, Reisi, M, \& Hasanzade A. Relationship between health literacy, health status, and healthy behaviors among older adults in Isfahan, Iran. J Educ Health Promot. 2012;1:31.

11. Zarcadoolas C, Pleasant A, \& Greer D. Understanding health literacy: an expanded model. Health Promot Int. 2005;20(2):195-203.

12. Philippine Council for Health Research and Development, Health Literacy [Online]. 2014 [cited 2017 December]. Available from http:// 
www.pchrd.dost.gov.ph/index.php/2012-05-23-07-46-36/2012-0524-00-03-06/3590-the-anti-stress-science-of-facebook

13. Senate S. No. 1315. National Health Literacy Act. 2013. Sixteenth Congress of the Republic of the Philippines. First Regular Session.

14. World Health Organization and U.S. National Institues of Health, Global Health and Aging [Online]. 2011 [Cited 2017 January] Available from http://www.who.int/ageing/publications/global_ health.pdf

15. Briones, M. et al. 2015. Health Literacy among Filipino Adults Belonging to Low-Income Families and its Association with Cancer Screening Utilization: A Cross-Sectional Study.

16. Virola R, Encarnacion J, Balamban B, Addawee M, Viernes M. 2013. Will the recent robust economic growth create a burgeoning middle class in the Philippines? 12th National Convention on Statistics. Mandaluyong City.
17. Khue, P, Ghiang H, and Thuc P. (2014 October). Health Literacy Survey in Haiphong City, Vietnam. Retrieved July 19, 2015.

18. Nakayama, K, Osaka, W, Togari T. et al. Comprehensive health literacy in Japan is lower than in Europe: a validated Japanese-language assessment of health literacy. BMC Public Health. 2015;15:505.

19. Duong, V, \& Chang P. 2014. Age and factors associated with health literacy among Taiwanese women. Taiwan.

20. Kirsch I, Jungeblut, A, Jenkins L, and Kolstad A. (1993). Adult Literacy in America: A First Look at the Results of the National Adult Literacy Survey (NALS). Washington, DC: National Center for Education Statistics.

21. Gutierrez N, Kindratt T, Pagels P, Foster B, and Gimpel N. Health literacy, health information seeking behaviors and internet use among patients attending a private and public clinic in the same geographic area. J Community Health. 2014:39(1),83-9.

The Acta Medica Philippina is now accepting original scientific papers, review articles and case reports for its upcoming issues. Please follow the format for submission as indicated in the "Instructions to Authors" elsewhere in the journal. All papers received shall be properly acknowledged. For inquiries and submission of proposals, please e-mail us at actamedicaphilippina@yahoo.com 